\title{
Antiepileptic drug exposure in pregnancy and pregnancy outcome from national drug usage data
}

\author{
Noni Richards ${ }^{1 *}$, David Reith ${ }^{2}$, Michael Stitely ${ }^{2}$ and Alesha Smith ${ }^{1,3}$
}

\begin{abstract}
Background: Antiepileptic drugs (AEDs) are used by pregnant women to manage conditions such as epilepsy and bipolar disorder even though they pose a risk to the developing foetus. This study aimed to determine the overall use of AEDs by women during their childbearing years and women who are pregnant and the association between AED use and rates of pregnancy termination and spontaneous abortion.

Methods: Retrospective population based cohort study using administrative databases in New Zealand between 2008 and 2014. Women who had been pregnant were identified by the National Minimum Dataset and were linked to the Pharmaceutical Collection to obtain information on use of AEDs. Women aged between 15 and 45 years dispensed AEDs were identified in the Pharmaceutical Collection.

Results: There was an increase in the number of women of child-bearing potential prescribed AEDs, from 9 women per 1000 women in 2008 to 11.4 women per 1000 women in 2014. Women who had been dispensed an AED had an increased rate of spontaneous abortion 8.97 spontaneous abortions per 100 pregnancies, compared with, 6.31 per 100 pregnancies (risk ratio $1.42,95 \% \mathrm{Cl} 1.40$ to 1.44), and a decreased rate of pregnancy termination, 18.51 terminations per 100 pregnancies compared with 19.58 per 100 pregnancies (risk ratio 1.95, 95\% Cl 0.94-0.96).

Conclusion: Use of newer AEDs is increasing in women of child-bearing potential in New Zealand leading to an overall increase in AED use in this group despite a fall in the use of older AEDs. AED use is this study was associated with an increased risk of spontaneous abortion and decreased rate of pregnancy termination, however confounding by indication could not be excluded.
\end{abstract}

Keywords: Antiepileptics, Pregnancy, Spontaneous abortion, Termination, Induced abortion, Administrative databases, Epilepsy, Bipolar disorder

\section{Key findings from study}

- The number of women of child bearing potential who are taking an AED is increasing over time with General Practitioners being the most common prescribers of AEDs to this group.

- The rate of spontaneous abortion is higher for women who have been dispensed an AED.

\footnotetext{
* Correspondence: noni.richards@otago.ac.nz

'School of Pharmacy, University of Otago, 18 Frederick St, Dunedin, New

Zealand

Full list of author information is available at the end of the article
}

\begin{abstract}
Background
Antiepileptic drugs (AEDs) are used by pregnant women even though they pose a risk to the developing foetus. They increase the risk of congenital malformations [1] and some, particularly sodium valproate, can cause developmental delay in children when used during pregnancy [2-4]. AED use during pregnancy has also been associated with other potential obstetric risks such as postpartum haemorrhage and intrauterine growth restriction, $[5,6]$ and some research suggests they increase the risk of spontaneous abortion and stillbirth although evidence is conflicting [6, 7]. Despite these risks, women with epilepsy typically continue treatment with AEDs during pregnancy to avoid the potentially harmful effect
\end{abstract}


of recurrent seizures which can have significant long term neurological and physical consequences to both themselves and their foetuses [8, 9]. Likewise, women with bipolar disorder often continue treatment with AEDs during pregnancy to minimise the risk of mood episode recurrence and its associated morbidity [10]. AEDs are also utilised for other neurological conditions such as migraine and pain.

Internationally researchers have found that overall use of AEDs is increasing despite declining use of the older generation AEDs [11]. This is thought to be the result of increasing use of the newer AEDs such as lamotrigine and levetiracetam and the utilisation of AEDs for a wider range of neurological uses, in particular for psychiatric conditions such as bipolar disorder [12, 13]. As a result there can be a wide range of health professionals who prescribe AEDs and this can create issues with continuity of care, particularly concerning the prescribing of concomitant birth control or providing preconception counselling in women of child-bearing age [14].

The aim of this whole of population study was to investigate the use of AEDs by women in New Zealand and determine pregnancy outcomes for women dispensed AEDs during pregnancy. The specific objectives were to determine the overall use of AEDs and patterns of use by women during their childbearing years and women who are pregnant in New Zealand and the association between AED use and rates of pregnancy termination and spontaneous abortion.

\section{Methods}

\section{Study population}

Using the National Health Index (NHI) all records from the Pharmaceutical Collection were linked to the National Minimum Dataset (NMDS) to identify women with no pregnancy, a birth, spontaneous abortion or pregnancy termination, to create the following cohorts:

1) Women of childbearing age (15-45 years old)

i) women aged between 15 and 45 years old who were dispensed a study AED three or more times in a 12 month period between January 1 , 2008 and December 31, 2014.

ii) estimated population of women in New Zealand aged between 15 and 45 years old [15].

2) Pregnant women

a) women who had a spontaneous abortion or pregnancy termination between January 1, 2009 and December 31, 2014 who:

i) had been dispensed any AED included in the study in the preceding 3 months.

ii) had NOT been dispensed any AED included in the study in the preceding 3 months. b) women in New Zealand who had a birth (including stillbirth) between January 1, 2009 and December 31, 2014 who:

i) had been dispensed any AED included in the study in the preceding 9 months.

ii) had NOT been dispensed any AED included in the study in the preceding 9 months.

Every person in New Zealand has a unique NHI number, an alphanumeric identifier that is used in all interactions with the health system over their life. This number makes it possible to link an individual's health data across a range of databases. The recording of NHIs are reliable from 2008, with $97 \%$ of all records containing an NHI therefore this study used data from the NMDS and the Pharmaceutical Collection between 2008 and 2014. Pregnancy outcomes starting from January 2009 were used to ensure consistent $\mathrm{NHI}$ recording 9 months prior.

The NMDS is a national collection of public and private hospital discharge information, including coded clinical data for both inpatients and day patients. Every hospital birth event (approximately 97\% of births in New Zealand) is captured by the NMDS. The NMDS also contains information about pregnancy terminations and spontaneous abortions that are managed in public hospitals. The Pharmaceutical Collection contains claim and payment information from pharmacists for all subsidised community dispensing in New Zealand (100\% of all subsidised medicines), however not those dispensed in hospital.

All study data contained only encrypted NHI numbers and no identifying details such as name or address were used. Any women missing an NHI number or with more than $20 \%$ of their data missing were excluded.

\section{Pregnancy outcomes}

To capture pregnancy outcomes in the NMDS database ICD 10 codes for abortion, ectopic pregnancy and birth were used, grouped as follows: spontaneous abortions (O02 - O039), pregnancy terminations or induced abortions (O040 - O049), and births, including stillbirths (Z370 Z375). Molar (O01) and ectopic pregnancies (O00) were excluded. To help ensure validity of the data and minimise incorrect coding issues, women with maternity codes who were under 15 years old or over 55 years old were excluded. Each pregnancy in the study time period was included.

Abortions are defined in New Zealand as foetal loss usually during the first 20 weeks of gestation. Induced abortions (pregnancy terminations) are those initiated voluntarily with the intent of terminating a pregnancy. All other abortions are considered spontaneous abortions. The legal definition of stillbirth in New Zealand is a child born dead who weighs $400 \mathrm{~g}$ or more or who is born after 20 completed weeks gestation. 


\section{Assessment of AED exposure}

In New Zealand, all AEDs are supplied by prescription and are subsidised if listed in the pharmaceutical schedule. The use of AEDs was defined as any prescription redeemed with drugs from the ATC code group Antiepileptics (N03AA) or subsidised under the "control of epilepsy" section of the schedule. This included the following medicines: carbamazepine, clobazam, clonazepam, ethosuximide, gabapentin, lacosamide, lamotrigine, levetiracetam, primidone, sodium valproate, topiramate and vigabatrin [16]. Dispensing information about the use of AEDs which are not subsidised, such as pregabalin and oxcarbazepine, is not captured by the pharmaceutical collection.

We defined any dispensing of an AED within 9 months of a birth or stillbirth or within 3 months of a spontaneous abortion or termination as an exposure to an AED in pregnancy. The date the medicine was dispensed determined at which stage during the pregnancy the exposure to an AED occurred. Exposure to polypharmacy was recorded for women who were dispensed two or more AEDs in the same trimester.

\section{Statistical analysis}

Rates of use (per population) and trends over time were determined using SPSS for pregnant women who were dispensed AEDs during the exposure period and for women of child bearing age (15-45 years) dispensed AEDs. Analysis of individual AEDs involved comparison of column proportions using $\mathrm{z}$ tests with a significance level of 0.05 (adjusted using the Bonferroni correction).

Incidence rates and risk ratios were generated for pregnancy outcomes comparing the cohort of women exposed to AED during pregnancy to those not exposed to AEDs during pregnancy. Advanced maternal age is a known risk factor for spontaneous abortion therefore risk ratios for spontaneous abortion and induced abortions were adjusted for maternal age by direct age-standardisation. Statistical significance was assumed if $p<0.05$.

\section{Ethical approval}

Approval for this study was granted by Human Research Ethics Committee at the University of Otago (HD15/020).

\section{Results}

\section{Women of child-bearing potential}

Over the study period, the number of women of childbearing age (between 15 and 45 years) dispensed any AED increased, from 9 women per 1000 women in 2008 to 11.4 women per 1000 women in 2014 (Fig. 1). During this time period, numbers of women dispensed sodium valproate or carbamazepine declined while the numbers of women dispensed lamotrigine, gabapentin, and levetiracetam increased. Prescriptions of AEDs to women of child-bearing age are most commonly provided by general practitioners, accounting for $60 \%$ of the prescriptions from 2008 to 2014 (Fig. 2).

\section{Pregnant women}

2284 individual women received an AED in the 9 months before a birth, or 3 months before a pregnancy termination or spontaneous abortion between 2009 and 2014 . 311 women had two pregnancies over the study period and 59 women had three or more pregnancies over this period which resulted in 2728 pregnancies. Table 1 shows the maternal age characteristics. Women dispensed an AED during this period were more likely to be older than women who had not been dispensed an AED $(p<0.05)$.

Overall, women who had been dispensed an AED in the exposure period (within 9 months of a birth or stillbirth or within 3 months of a spontaneous abortion or pregnancy termination) had an increased rate of spontaneous

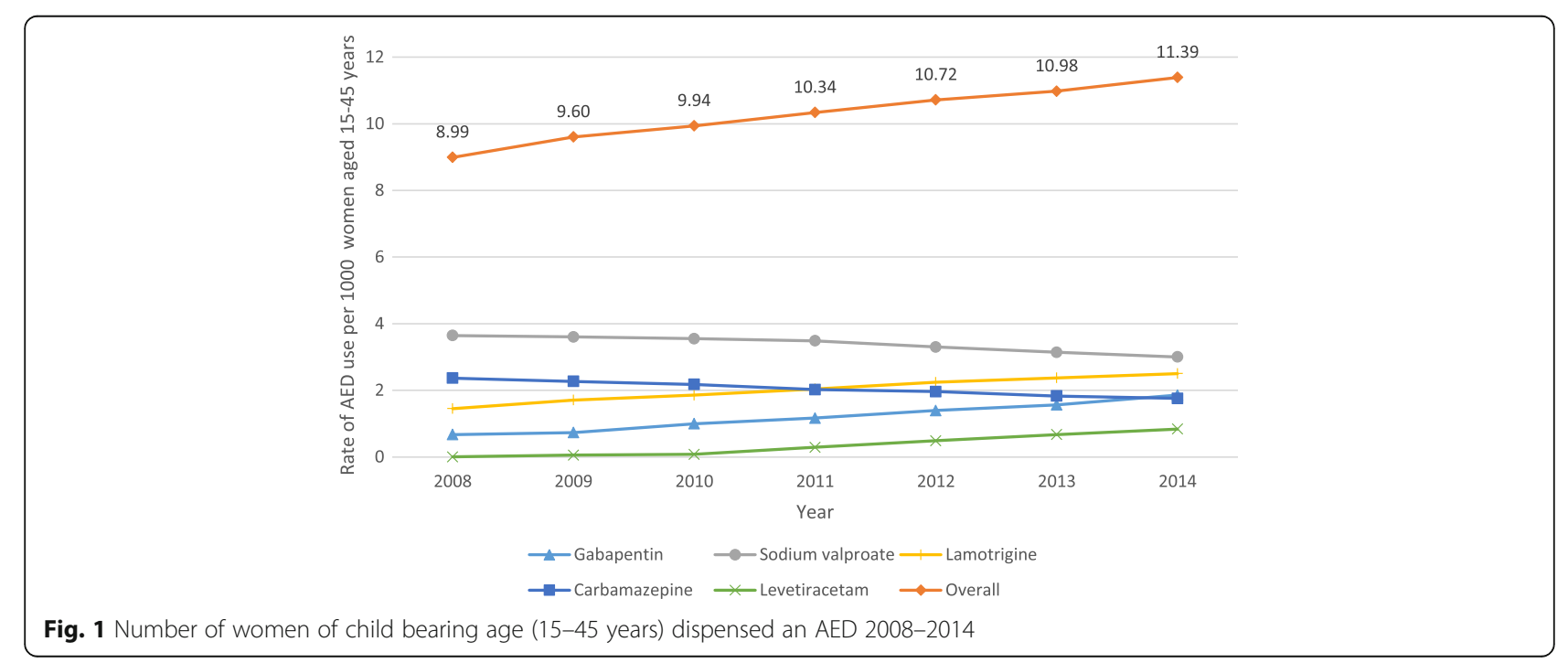




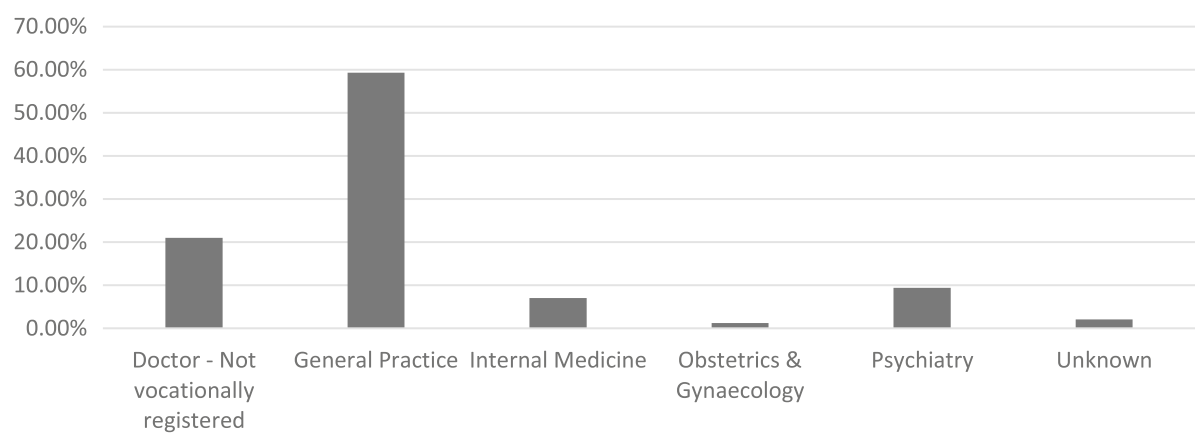

Fig. 2 AED prescribing to women of child-bearing age by provider type 2008-2014

abortion, 8.97 per 100 pregnancies, than those not dispensed an AED, 6.31 per 100 pregnancies (age-adjusted risk ratio 1.42 , $95 \%$ CI 1.40 to 1.44 ) (Table 2). Women dispensed an AED had a decreased rate of pregnancy termination, 18.51 per 100 pregnancies compared with 19.50 per 100 pregnancies for women who had not been dispensed an AED (age-adjusted risk ratio 0.95, 95\% CI $0.94-0.96$ ).

Analysis of pregnancy outcomes by AED, where women were only exposed to one AED during pregnancy and where there were 50 or more exposures, revealed no difference in the rate of spontaneous abortions between AEDs. Women that had a termination were more likely to be taking clonazepam, gabapentin or sodium valproate than lamotrigine or carbamazepine. Women that gave birth were more likely to be taking carbamazepine or lamotrigine than clonazepam, gabapentin or sodium valproate.

Overall use of AEDs by pregnant women increased slightly from 8.10 per 1000 births in 2009 to 9.18 per 1000 births in 2014. During this time, use of sodium valproate by pregnant women nearly halved from 2.24 women per 1000 births to 1.20 women per 1000 births while use of gabapentin ( 0.27 to 0.97 women per 1000 births), lamotrigine (1.10 to 1.79 women per 1000 births) and levetiracetam (from 0 to 0.83 women per 1000 births) increased among pregnant women (Fig. 3).
The majority of pregnant women dispensed AEDs during pregnancy are on monotherapy, only a small proportion (10.7\%) were on AED polytherapy during pregnancy. In the time period from 2009 to 2014, of the women dispensed any AED during the nine months before birth, 171 (8.65\%) were dispensed two different AEDs in the same trimester. 35 women (1. 77\%) were dispensed three AEDs and five (0.25\%) women were dispensed four AEDs in the nine months before birth.

\section{Discussion}

In this population based cohort study, we observed a higher rate of spontaneous abortion and lower rate of pregnancy termination in women who had been dispensed AEDs compared with women who had not been dispensed AEDs during pregnancy. There was also a statistically significant increase in the number of women of child-bearing age being dispensed AEDs over the study time period. Use of the sodium valproate declined over the time period while use of the newer generation AEDs, such as lamotrigine, increased. A similar trend was seen among women who were pregnant however this did not reach statistical significance. The majority of pregnant women dispensed AEDs during pregnancy are on monotherapy. With most

Table 1 Pregnancies by maternal age (years) 2009-2014

\begin{tabular}{|c|c|c|c|c|c|c|c|c|}
\hline \multicolumn{5}{|c|}{ Using AEDs ( $n=2943)$} & \multicolumn{4}{|c|}{ Not using AEDs $(n=469,816)$} \\
\hline Age band (years) & Spontaneous abortion & Pregnancy termination & Birth & Total & Spontaneous abortion & Pregnancy termination & Birth & Total \\
\hline $15-19$ & 8 & 26 & 66 & $110(3.7)$ & 1461 & 16,427 & 17,773 & $35,661(7.6)$ \\
\hline $20-24$ & 33 & 112 & 349 & $494(18.1)$ & 4175 & 28,612 & 62,266 & $95,053(20.2)$ \\
\hline $25-29$ & 47 & 130 & 520 & $697(25.5)$ & 5652 & 19,779 & 85,962 & $111,393(23.7)$ \\
\hline $30-34$ & 65 & 105 & 547 & $717(26.3)$ & 7371 & 13,430 & 99,448 & $120,249(25.6)$ \\
\hline $35-39$ & 56 & 72 & 346 & $474(17.4)$ & 6746 & 9275 & 64,947 & $80,968(17.2)$ \\
\hline $40-44$ & 42 & 45 & 140 & $227(8.3)$ & 3734 & 3772 & 17,176 & $24,682(5.3)$ \\
\hline$>45$ & 4 & 6 & 9 & $19(0.7)$ & 485 & 316 & 1009 & $1810(0.4)$ \\
\hline Total & 255 & 496 & 1977 & $2728(100.0)$ & 29,624 & 91,611 & 348,581 & $469,816(100.0)$ \\
\hline
\end{tabular}


Table 2 Association between AED use during pregnancy and spontaneous abortion and pregnancy termination rates

\begin{tabular}{|c|c|c|c|c|}
\hline \multicolumn{5}{|c|}{ Spontaneous abortion } \\
\hline AED use & Spontaneous abortion & Total Pregnancies & Incidence rate ${ }^{\mathrm{a}}(95 \% \mathrm{Cl})$ & Risk ratio $(95 \% \mathrm{Cl})$ \\
\hline \multirow[t]{2}{*}{ AEDs } & \multirow[t]{2}{*}{255} & \multirow[t]{2}{*}{2728} & 9.35 (8.31 to 10.50$)$ & $\begin{array}{l}1.48(1.32-1.67) \\
P<0.0001\end{array}$ \\
\hline & & & $\begin{array}{l}\text { Age-adjusted rate } \\
8.97 \text { (8.89 to 9.05) }\end{array}$ & $\begin{array}{l}\text { Age adjusted risk ratio } \\
1.42(1.40-1.44) \\
P<0.0001\end{array}$ \\
\hline No AEDs & 29,624 & 469,816 & 6.31 (6.24 to 6.38 ) & \\
\hline \multicolumn{5}{|c|}{ Pregnancy termination } \\
\hline AED use & Pregnancy termination & Total Pregnancies & Incidence rate ${ }^{a}(95 \% \mathrm{Cl})$ & Risk ratio $(95 \% \mathrm{Cl})$ \\
\hline \multirow[t]{2}{*}{ AEDs } & \multirow[t]{2}{*}{496} & \multirow[t]{2}{*}{2728} & 18.18 (16.78 to 19.67$)$ & $\begin{array}{l}0.93(0.86-1.01) \\
P=0.0860\end{array}$ \\
\hline & & & $\begin{array}{l}\text { Age-adjusted rate } \\
18.51 \text { (18.40 to } 18.62)\end{array}$ & $\begin{array}{l}\text { Age adjusted risk ratio } \\
0.95(0.94-0.96) \\
P<0.0001\end{array}$ \\
\hline No AEDs & 91,998 & 469,816 & 19.58 (19.47 to 19.70$)$ & \\
\hline
\end{tabular}

${ }^{\mathrm{a} P e r} 100$ pregnancies; ${ }^{\mathrm{b}}$ Age-adjusted rate calculated using the cohort of unexposed women as a reference group

prescriptions for AEDs in women of child-bearing potential provided by general practitioners.

It is inherently difficult to investigate the rate of spontaneous abortion in women treated with AEDs because they often occur early in pregnancy and may not be recognised and recorded. However studies which have investigated pregnancy outcomes, including rates of spontaneous abortion, after exposure to AEDs during pregnancy have found conflicting results $[6,17]$. A recent large meta-analysis assessing the association between epilepsy, AED exposure and pregnancy outcomes found that women with a diagnosis of epilepsy had a significantly increased rate of spontaneous abortion however exposure to AEDs was not associated with an increased risk [6]. Another study found a small but statistically significant elevated risk of spontaneous abortion in women who took AEDs but concluded that it was likely to be the result of confounding by indication [17]. This present study found an increased rate of spontaneous abortion among women prescribed AEDs. While these results were statistically significant we could not control for some confounding factors so cannot exclude the possibility that there was confounding by indication or lifestyle. The rate of spontaneous abortion among both exposed and unexposed women was low compared to other studies. This likely reflects the way data is captured in New Zealand (only data on spontaneous abortions managed in hospital are collected). In addition, in this study we excluded ectopic pregnancy and molar pregnancy and these are often included in commonly cited spontaneous abortion rates. In recent years, guidelines have moved toward recommending conservative management as a first line and these women will be largely missing in the NMDS. Studies have found that up to $50 \%$ of spontaneous abortions are managed at home, [18] which from our data would estimate the general rate of spontaneous abortion in New Zealand as $12.62 \%$.

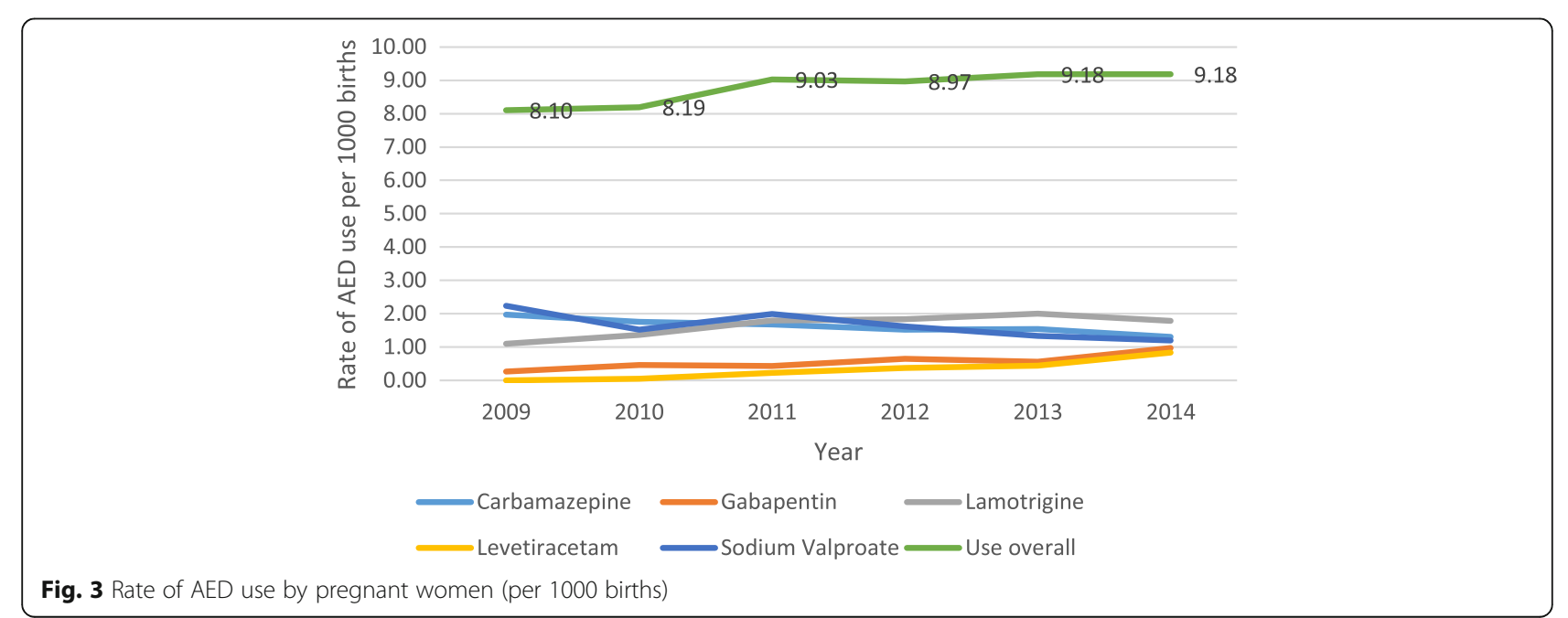


AEDs are commonly used to manage other serious psychiatric disorders such as bipolar disorder. Currently there are a paucity of data regarding the association between bipolar disorder and rates of spontaneous abortion. Studies examining the effect of untreated psychiatric illness on obstetrical outcome have found that antenatal stress and anxiety are linked to adverse outcomes such as preterm birth and low birth-weight $[19,20]$. It is unknown whether bipolar disorder increases the risk of spontaneous abortion, however it may be possible that symptoms of bipolar disorder or associated behaviours, such as smoking [21], may increase the likelihood of spontaneous abortion and contribute to confounding by indication in this study.

Studies which have included pregnancy termination data have found high rates of termination among women who have taken AEDs [22, 23]. One study found higher pregnancy termination rates among women taking AEDs compared with women not taking AEDs and found the rate of termination was particularly high among women taking AEDs for conditions other than epilepsy [22]. We included pregnancy termination data in this study and found a small but statistically significant decrease in the rate of pregnancy terminations in women who had been dispensed AEDs. There is a possibility that this rate is underestimated due to the termination data missing from private clinics.

International studies looking at AED use among women of child-bearing potential have found that their use is increasing due to increased and wider availability of the newer generation AEDs [11, 24-26]. A study from the UK investigating AED use among adolescent girls found a significant decrease in prescriptions for carbamazepine and sodium valproate and a 10-fold increase in prescriptions for lamotrigine over the same time period [25]. Our results appear to confirm this trend in New Zealand, with overall use of AEDs in women of child-bearing potential increasing over time.

A study in the US [26], found a significant increase in AED prescribing in pregnant women as a result of increasing use of AEDs among pregnant women with diagnoses for psychiatric and pain disorders but not among those with epilepsy diagnoses. In another study, the overall rate of AED use among pregnant women enrolled in Medicaid did not change significantly over time however use of older generation AEDs declined while use of the newer generation AEDs increased [27]. This present study yielded similar results as the number of pregnant women using AEDs in our study did not vary as much over the time period but showed a similar trend towards decreased use of sodium valproate.

\section{Strengths}

The NMDS captures all births, pregnancy terminations and spontaneous abortions which occur in public hospitals within New Zealand. All AEDs in New Zealand are prescription medicines, therefore the Pharmaceutical Collection captures virtually $100 \%$ of the dispensing of AEDs in community pharmacies in New Zealand. By combining the Pharmaceutical Collection and the NMDS, data from the majority of the female population in New Zealand who are pregnant or of child-bearing age and exposed to AEDs over a six year period is captured. Deriving this data from the whole population reduces the risk of selection bias and there is also no loss to follow up of the study subjects. In addition it allows the capture of information about AED use among women using them for any condition rather than only for a particular condition such as epilepsy.

\section{Limitations}

Data regarding pregnancy termination in private hospitals and spontaneous abortions not managed in hospital are missing from the NMDS. This accounts for approximately 5000 terminations per year and an unknown number of early spontaneous abortions. The total number of terminations and spontaneous abortions are therefore underestimated by the NMDS. If the pattern of health care utilisation is evenly distributed between exposed and unexposed women then observed differences are valid. The determination of the exposure window in this study was unspecific to some extent and there may be some women not captured by this method. The narrow window increases the likelihood of exposure to AEDs while pregnant in the cohort of women identified.

The NMDS had incomplete information on factors such as smoking status, diagnosis, education of mother, individual patient living circumstances, use of unsubsidized medicines or over-the-counter medicine use. These factors can influence pregnancy outcomes such as the likelihood of pregnancy termination or spontaneous abortion. Without this information it was difficult to control for confounding therefore there is a possibility the differences in outcomes seen between women dispensed AEDs and those not dispensed AEDs are the result of lifestyle factors or the underlying condition AEDs are being used to treat. Using administrative data assumes that the women takes the medicine as prescribed, at the time it is dispensed and that they take it at all. Studies investigating the correlation between self-reported medicine use and administrative data have found a good correlation for chronic conditions such as epilepsy [28].

\section{Conclusions}

This study found the rates of AED use are increasing among women of child-bearing potential in New Zealand 
with General Practitioners being the most common prescribers of AEDs to this group. This has implications for education to primary care practitioners and women in this age group as it is likely that this trend will continue, seeing more women exposed to AEDs during pregnancy both in New Zealand and internationally. Along with the well documented risk of foetal malformations with some AEDs this study found there may be additional risks for pregnant women using AEDs such as an elevated risk of spontaneous abortion.

\section{Abbreviations}

AED: Antiepileptic drug; NHI: National health index; NMDS: National Minimum dataset (hospital discharges)

\section{Acknowledgements}

Abstract presented at the 16th European Society for Developmental Perinatal and Paediatric Congress [29]

\section{Funding}

NR is supported by a doctoral scholarship from the University of Otago. The funding source has no role in the design and conduct of the study; the collection, analysis and interpretation of data; or the preparation, review, or approval of the manuscript.

\section{Availability of data and materials}

The data that support the findings of this study are available from the New Zealand Ministry of Health but restrictions apply to the availability of these data, which were used under agreement for the current study and so are not publicly available. Data are however available from the authors upon reasonable request and with permission from the Ministry of Health.

\section{Authors' contributions}

NR, DR, MS, and AS conceived and designed the study. NR and AS acquired the data. All authors contributed to the analyses and interpretation of the data and drafting the manuscript. Final version of the manuscript read and approved by all authors.

\section{Ethics approval and consent to participate}

Ethical approval for this study was granted by Human Research Ethics Committee at the University of Otago (HD15/020). Administrative permission to access and use the data was obtained from the New Zealand Ministry of Health.

\section{Consent for publication}

Not applicable.

\section{Competing interests}

The authors declare that they have no competing interests.

\section{Publisher's Note}

Springer Nature remains neutral with regard to jurisdictional claims in published maps and institutional affiliations.

\section{Author details}

'School of Pharmacy, University of Otago, 18 Frederick St, Dunedin, New Zealand. 'Department of Women's and Children's Health, Dunedin School of Medicine, University of Otago, Dunedin, New Zealand. ${ }^{3}$ bpacnz, 10 George St, Dunedin, New Zealand.

Received: 18 May 2017 Accepted: 29 March 2018

Published online: 06 April 2018

\section{References}

1. Ban L, Fleming KM, Doyle P, Smeeth L, Hubbard RB, Fiaschi L, Tata L. Congenital anomalies in children of mothers taking antiepileptic drugs with and without Periconceptional high dose folic acid use: a population-based cohort study. PLoS One. 2015;10(7):e0131130.
2. Veiby G, Daltveit AK, Schjøllberg S, Stoltenberg C, Øyen AS, Vollset SE, Engelsen BA, Gilhus NE. Exposure to antiepileptic drugs in utero and child development: a prospective population-based study. Epilepsia. 2013;54(8):1462-72.

3. Bromley RL, Mawer GE, Briggs M, Cheyne C, Clayton-Smith J, García-Fiñana M, Kneen R, Lucas SB, Shallcross R, Baker GA. The prevalence of neurodevelopmental disorders in children prenatally exposed to antiepileptic drugs. J Neurol Neurosurg Psychiatry. 2013;84(6):637-43.

4. Meador KJ, Baker GA, Browning N, Cohen MJ, Bromley RL, Clayton-Smith J, Kalayjian LA, Kanner A, Liporace JD, Pennell PB. Fetal antiepileptic drug exposure and cognitive outcomes at age 6 years (NEAD study): a prospective observational study. Lancet Neurol. 2013;12(3):244-52.

5. Borthen I, Eide MG, Daltveit AK, Gilhus NE. Delivery outcome of women with epilepsy: a population-based cohort study. BJOG. 2010;117(12):1537-43.

6. Viale L, Allotey J, Cheong-See F, Arroyo-Manzano D, McCorry D, Bagary M, Mignini L, Khan KS, Zamora J, Thangaratinam S, et al. Epilepsy in pregnancy and reproductive outcomes: a systematic review and meta-analysis. Lancet. 2015:386(10006):1845-52.

7. Thomas SV, Sindhu K, Ajaykumar B, Sulekha Devi PB, Sujamol J. Maternal and obstetric outcome of women with epilepsy. Seizure. 2009;18(3):163-6.

8. Sperling MR. The consequences of uncontrolled epilepsy. CNS spectrums. 2004;9(02):98-109.

9. Gilboa SM, Broussard CS, Devine OJ, Duwe KN, Flak AL, Boulet SL, Moore CA, Werler MM, Honein MA. Influencing clinical practice regarding the use of antiepileptic medications during pregnancy: modeling the potential impact on the prevalences of spina bifida and cleft palate in the United States. Am J Med Genet C: Semin Med Genet. 2011;157C(3):234-46.

10. Viguera AC, Whitfield T, Baldessarini RJ, Newport DJ, Stowe Z, Reminick A, Zurick A, Cohen LS. Risk of recurrence in women with bipolar disorder during pregnancy: prospective study of mood stabilizer discontinuation. Am J Psychiatry. 2007;164(12):1817-24. quiz 1923

11. Nicholas JM, Ridsdale L, Richardson MP, Ashworth M, Gulliford MC. Trends in antiepileptic drug utilisation in UK primary care 1993-2008: cohort study using the general practice research database. Seizure. 2012;21(6):466-70.

12. Adedinsewo DA, Thurman DJ, Luo YH, Williamson RS, Odewole OA, Oakley GP Jr. Valproate prescriptions for nonepilepsy disorders in reproductive-age women. Birth Defects Res A Clin Mol Teratol. 2013;97(6):403-8.

13. Vajda FJ, Hollingworth S, Graham J, Hitchcock AA, O'Brien TJ, Lander CM, Eadie MJ. Changing patterns of antiepileptic drug use in pregnant Australian women. Acta Neurol Scand. 2010;121(2):89-93.

14. Fairgrieve $S D$, Jackson $M$, Jonas $P$, Walshaw $D$, White $K$, Montgomery $T L$, Burn J, Lynch SA. Population based, prospective study of the care of women with epilepsy in pregnancy. BMJ. 2000;321(7262):674-5.

15. New Zealand Government: Population statistics. In: StatsNZ infoshare. [www.stats.govt.nz]. Accessed 21 Dec 2016.

16. ATC/DDD Index 2016 [http://www.whocc.no/atc_ddd_index/]. Accessed 15 Sept 2016.

17. Bech BH, Kjaersgaard MI, Pedersen HS, Howards PP, Sorensen MJ, Olsen J, Parner ET, Pedersen LH, Vestergaard M, Christensen J. Use of antiepileptic drugs during pregnancy and risk of spontaneous abortion and stillbirth: population based cohort study. BMJ. 2014;349:95159.

18. Spontaneous abortion in primary care. A report from ASPN. J Am Board Fam Pract. 1988; 1 (1):15-23.

19. Dole N, Savitz DA, Hertz-Picciotto I, Siega-Riz AM, McMahon MJ, Buekens P. Maternal stress and preterm birth. Am J Epidemiol. 2003;157(1):14-24.

20. Wadhwa PD, Sandman CA, Porto M, Dunkel-Schetter C, Garite TJ. The association between prenatal stress and infant birth weight and gestational age at birth: a prospective investigation. Am J Obstet Gynecol. 1993;169(4): $858-65$.

21. Hyland A, Piazza KM, Hovey KM, Ockene JK, Andrews CA, Rivard C, Wactawski-Wende J. Associations of lifetime active and passive smoking with spontaneous abortion, stillbirth and tubal ectopic pregnancy: a crosssectional analysis of historical data from the Women's Health Initiative. Tob Control. 2015;24(4):328-35.

22. Cassina M, Dilaghi A, Di Gianantonio E, Cesari E, De Santis M, Mannaioni G, Pistelli A, Clementi M. Pregnancy outcome in women exposed to antiepileptic drugs: teratogenic role of maternal epilepsy and its pharmacologic treatment. Reprod Toxicol. 2013;39:50-7.

23. Kulaga S, Sheehy O, Zargarzadeh AH, Moussally K, Berard A. Antiepileptic drug use during pregnancy: perinatal outcomes. Seizure. 2011;20(9):667-72.

24. Man SL, Petersen I, Thompson M, Nazareth I. Antiepileptic drugs during pregnancy in primary care: a UK population based study. PLoS One. 2012;7(12):e52339. 
25. Ackers R, Besag FM, Wade A, Murray ML, Wong IC. Changing trends in antiepileptic drug prescribing in girls of child-bearing potential. Arch Dis Child. 2009;94(6):443-7.

26. Bobo WV, Davis RL, Toh S, Li DK, Andrade SE, Cheetham TC, Pawloski P, Dublin S, Pinheiro S, Hammad T, et al. Trends in the use of antiepileptic drugs among pregnant women in the US, 2001-2007: a medication exposure in pregnancy risk evaluation program study. Paediatr Perinat Epidemiol. 2012;26(6):578-88.

27. Wen X, Meador KJ, Hartzema A. Antiepileptic drug use by pregnant women enrolled in Florida Medicaid. Neurology. 2015;84(9):944-50.

28. Pisa FE, Casetta A, Clagnan E, Michelesio E, Vecchi Brumatti L, Barbone F. Medication use during pregnancy, gestational age and date of delivery: agreement between maternal self-reports and health database information in a cohort. BMC Pregnancy Childbirth. 2015;15:310.

29. Richards R, Smith S. O-31 Antiepileptic drug (aed) exposure in pregnancy and pregnancy outcome from national drug usage data. Arch Dis Child. 2017:102(10):A14-5.

Submit your next manuscript to BioMed Central and we will help you at every step:

- We accept pre-submission inquiries

- Our selector tool helps you to find the most relevant journal

- We provide round the clock customer support

- Convenient online submission

- Thorough peer review

- Inclusion in PubMed and all major indexing services

- Maximum visibility for your research

Submit your manuscript at www.biomedcentral.com/submit 